\title{
Unilateral Koilonychia Secondary to Chemical Depilatory Product
}

\author{
Isha Gupta Meha Tyagi Surabhi Dayal Jayanti Singh
}

Department of Dermatology, Venereology and Leprosy, Pandit B.D Sharma Post Graduate Institute of Medical Sciences, Rohtak, India

\section{Established Facts}

- Koilonychia (spoon-shaped nails) is characterized by the reversion of the curvature in the transverse and longitudinal axes of the nail plate. The lateral edges become upwards everted and the nail appears thinner and concave, giving rise to the typical "spoon" shape.

- Koilonychia has diverse aetiologies that may be hereditary, acquired, or idiopathic. Common associations are iron deficiency anaemia, Plummer Vinson syndrome, hyperthyroidism, systemic lupus erythematosus, Raynaud phenomenon, nutritional deficiencies, traumatic and occupational aetiologies. In children, koilonychia of toe nail is transient or idiopathic.

\section{Novel Insights}

- Acute unilateral koilonychia due to chemical depilatory products has not been described in the literature. Nails and hair both contain nearly similar sulphur-rich keratins, making them suitable targets for chemical depilatory products. Hence, we emphasize the importance of nail protection while using chemical depilatories to avoid any undue side effects.

\section{Keywords}

Unilateral koilonychia $\cdot$ Chemical depilatories $\cdot$ Hair removal

\section{Abstract}

Excess hair is a problem for both men and women who want to conform to today's cosmetic social norms. Chemical depilatories are a safe, fast, and inexpensive method of hair removal. The most commonly used depilatory agents are thioglycolates and to a lesser extent, sulphides. The most common side effect of chemical depilatories is irritant contact dermatitis. However, allergic contact dermatitis is rare and may be related to lanolin, fragrance, or thioglycolate itself. Unilateral koilonychia as a side effect of chemical depilato-

karger@karger.com www.karger.com/sad

Karger ries has not been described previously in the literature. We report this case due to its rarity and highlight the significance of nail protection while using chemical depilatory products.

(c) 2020 S. Karger AG, Basel

\section{Introduction}

Koilonychia is characterized by the reversion of the curvature in the transverse and longitudinal axes of the nail plate. The lateral edges become upwards everted, and the nail appears thinner and concave, giving rise to the typical "spoon" shape [1]. Koilonychia has diverse aeti- 


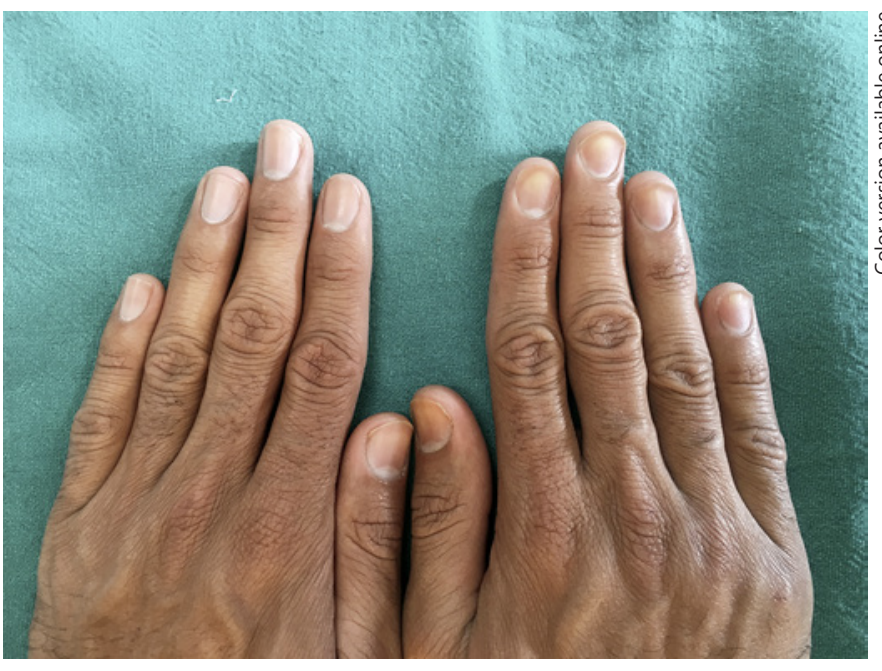

Fig. 1. Yellowish discolouration and thinning and depression of fingernails of the right hand with elevation of distal edges (spoonshaped nails).

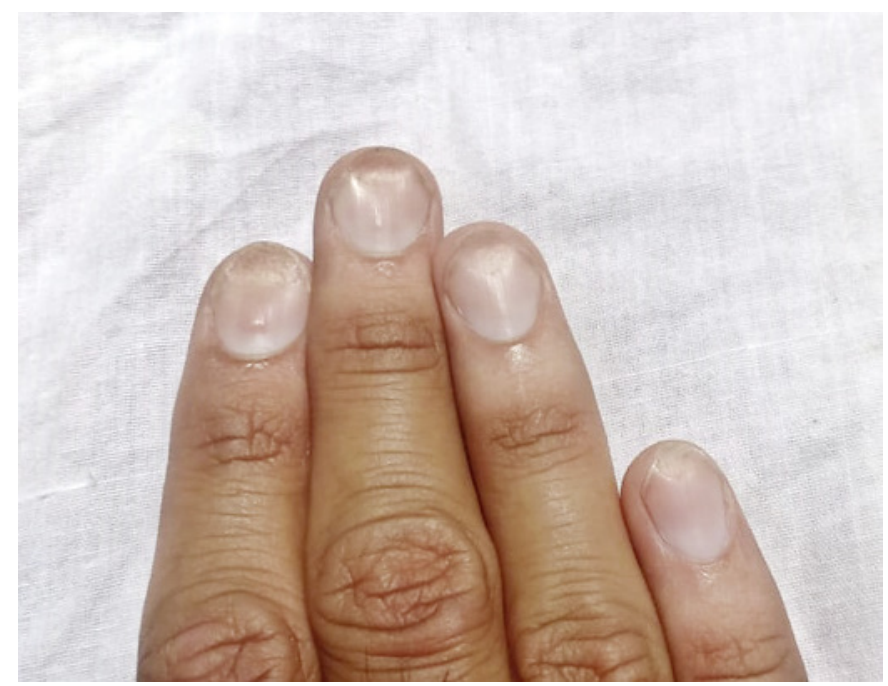

Fig. 3. Fingernails of the right hand showing partial response with improvement in three-fourths of nails, leaving the distal onefourth, at the 2.5-month follow-up.

ologies that may be hereditary, acquired, or idiopathic. Common associations are iron deficiency anaemia, Plummer Vinson syndrome, hyperthyroidism, systemic lupus erythematosus, Raynaud phenomenon, nutritional deficiencies, traumatic and occupational aetiologies. In children, koilonychia of toe nail is transient or idiopathic [2]. We describe the case of a 24-year-old man who suddenly

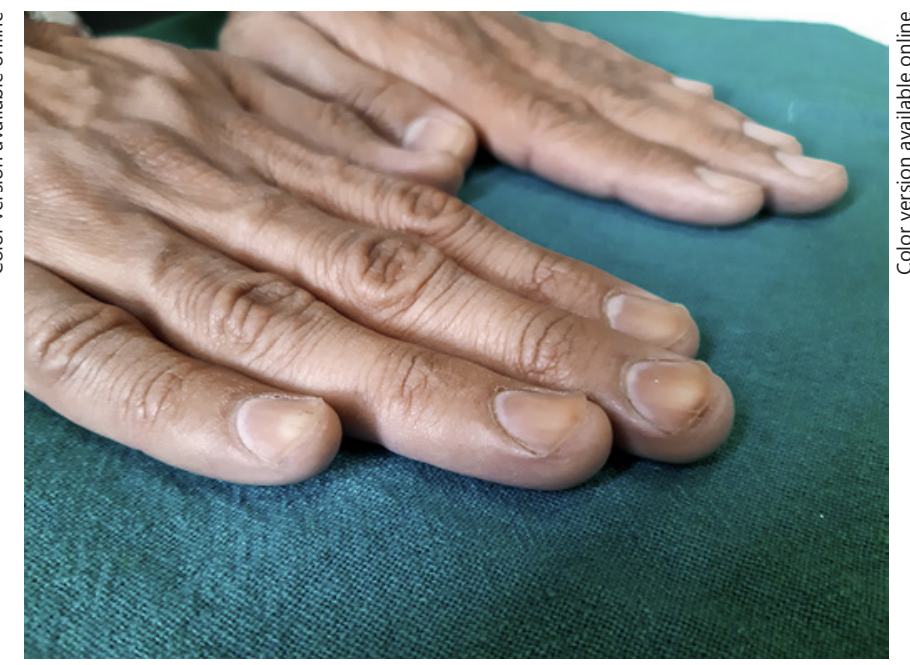

Fig. 2. Side view showing concavity and elevation of distal edges (koilonychia), mild scaling on the proximal nail fold, and whitish discolouration along the proximal edge of the nails following the borders of nail folds.

developed koilonychia after preparing a mixture for chemical depilation by dissolving a hair removal soap in water.

\section{Case Report/Case Presentation}

A 24-year-old man reported to our department with chief complaints of sudden development of depression and thinning of all nails of his right hand along with elevation at the distal margins for 2 days. The patient had prepared a solution for chemical depilation by dissolving a locally available hair removal soap in water and used his right hand for stirring it for $15 \mathrm{~min}$, after which he developed the presenting complaint. There was no history of any complaint on the site of application of the solution for hair removal. There was no prior history of trauma or use of any drugs or chemicals such as nail polish and detergents. The family history was not significant.

On examination, the nails of his right hand were pale yellow in colour towards the distal margin. The nail plates appeared spoon shaped with thin and depressed nail plates with concavity at distal margins in all the 5 nails of his right hand (Fig. 1). Fingernails of the right hand showed ragged cuticles, and longitudinal red streaks suggestive of splinter haemorrhages were visible on the right fifth fingernail. There was mild scaling on the proximal nail fold and whitish discolouration along the proximal edge of the nail following the borders of the nail folds (Fig. 2). Nail examination of the left hand was normal. The remaining cutaneous and general physical examinations were normal. Laboratory investigations that included complete haemogram, serum ferritin, liver and renal function tests, and thyroid profile were normal. Patch testing and nail arsenic level assessment could not be performed due to unavailabilty of the testing facilities at our centre. However, there were no signs of inflammation over the site of application of the chemical 
depilation solution. Chemical testing of the product revealed barium sulphide $5 \%$ as the active depilatory agent along with China clay; mineral oil; perfumes made from furfural, azulene, Myroxylon, and ethereal acetaldehyde; and starch such as amylose and amylopectin. The patient was asked to avoid trauma and irritants like soap and detergents, and partial response was seen after 2.5 months (Fig. 3).

So, sudden onset of koilonychia after dissolving a chemical depilatory soap for $15 \mathrm{~min}$ and development of koilonychia unilaterally on the right hand that was used for dissolution of the chemical pointed towards the irritant nature of chemicals. Therefore, based on clinical history and examination, the diagnosis of unilateral koilonychia secondary to irritant contact dermatitis due to chemical depilatory product was made.

\section{Discussion/Conclusion}

Excess hair is a problem for both men and women who want to conform to today's cosmetic social norms. There are 2 types of hair removal methods: depilation and epilation. Depilation is the sole removal of the hair shaft, not affecting the hair bulb, which lasts for 2 weeks, whereas epilation is the removal of the entire hair shaft and bulb with results lasting 6-8 weeks [3]. Chemical hair removal products are an inexpensive, fast, and painless method of depilation [4]. The most commonly used depilatory agents are thioglycolates and to a lesser extent, sulphides [5]. They function by disrupting the disulphide bonds, which destabilizes keratin. This weakens the hair, which can be easily wiped off the surface $[3,5]$. Alkali is added to increase the $\mathrm{pH}$ and, hence, the efficacy of the product [5]. In developing countries, arsenic- and sulphur-containing products are increasingly being used for hair removal after misnaming them purposely as plant or natural products so that they become preferable agents. Arsenic attaches to the sulphydryl group and accumulates in keratinized tissue, and can have serious lethal effects [4]. The most common side effect of chemical depilatory products is irritant contact dermatitis [4]. However, allergic contact dermatitis is rare and may be related to lanolin, fragrance, or thioglycolate itself [5]. Strontium, calcium, and barium sulphide depilatories are inherently faster and more effective hair removers but are also more irritating than thioglycolates [5].

Our patient also developed unilateral koilonychia due to a chemical depilatory product. The probable hypothesis is that both hair and nail plate and matrix possess nearly similar hard keratins - KRT31-34 (type 1) and KRT81-84 (type 2). As compared to epithelial keratins, they possess more sulphur in their head and tail domains, which allows them to form more tight cross links via di- sulphide bonds [6]. Therefore, both hair and nails are susceptible targets of chemical depilatory agents. In our case, chemical depilatory products probably led to dissolution of the nails by acting on the disulphide bonds present in sulphur-rich keratins present in the nails. Alanko et al. [7] reported painful finger tips and spooning of nails in hairdressers who give permanent waves with ammonium thioglycolate over time, without associated dermatitis. The second hypothesis is that prolonged contact with an alkali in a chemical depilatory product leads to thinning and softening of nails, making them easily deformable. Koilonychia due to alkali has been reported in cement workers/bricklayers [1].

Common associations of koilonychia are iron deficiency anaemia, Plummer Vinson syndrome, hyperthyroidism, systemic lupus erythematosus, Raynaud phenomenon, nutritional deficiencies, and traumatic and occupational aetiologies [2]. Occupational koilonychia has been reported in cabinetmakers exposed to organic solvents, car mechanics, and oil-burner repairers exposed to oils. In addition, it has been the result of repeated mechanical trauma in mushroom-growers, slaughterhouse workers, coil winders, and rickshaw pullers [7].

There is only a single case report of koilonychia of all fingernails due to arsenic present in chemical depilatory products; however, in our patient, koilonychia was present unilaterally probably due to barium sulphide present as an active depilatory agent in the soap [2]. In conclusion, the product should be correctly labelled, mentioning the names of active ingredients, their concentration, and $\mathrm{pH}$, and appropriate instructions should be given regarding usage of the product, duration of contact, appropriate formulations like lotions or gel in place of soaps and powders, and protection of nail plate by use of gloves or inert occlusive films and use of spatulas so as to avoid any undue side effects.

\section{Acknowledgements}

We would like to thank Professor Gajendra Singh, Principal, College of Pharmacy, Pandit B.D. Sharma University of Health Sciences for his valuable contribution.

\section{Statement of Ethics}

All procedures followed were in accordance with the ethical standards of the responsible committee on human experimentation (institutional and national) and with the Helsinki Declaration of 1964, as revised in 2013. The patient gave his written informed consent to publish the case and images. 


\section{Conflict of Interest Statement}

The authors have no conflicts of interest to declare.

\section{Author Contributions}

I.G. and M.T. prepared the manuscript. All authors read and approved the final version.

\section{Funding Sources}

No funding or sponsorship was received for this article.

\section{References}

1 Balestri R, Rech G, Girardelli CR, Piraccini $\mathrm{BM}$, La Placa M. Acute koilonychia of fingernails due to lye. Skin Appendage Disord. 2017;2(3-4):183-4.

2 Walker J, Baran R, Vélez N, Jellinek N. Koilonychia: an update on pathophysiology, differential diagnosis and clinical relevance. J Eur Acad Dermatol Venereol. 2016;30(11): 1985-91.
3 Fernandez AA, França K, Chacon AH, Nouri K. From flint razors to lasers: a timeline of hair removal methods. J Cosmet Dermatol. 2013;12(2):153-62.

4 Pancar GS, Kalkan G. Irritant nail dermatitis of chemical depilatory product presenting with koilonychia. Cutan Ocul Toxicol. 2014; 33(1):87-9.
5 Olsen EA. Methods of hair removal. J Am Acad Dermatol. 1999;40(2 Pt 1):143-7.

6 Wang E, Berker DD, Christiano AM. Biology of hair and nails. In: Bolognia JL, Schaffer JV, Cerroni L, editors. Dermatology. 4th ed. China: Elsevier; 2018. p. 1144-59.

7 Alanko K, Kanerva L, Estlander T, Jolanki R, Leino T, Suhonen R. Hairdresser's koilonychia. Am J Contact Dermatitis. 1997;8(3): $177-8$ 